\title{
Movement parameters of persons with disabilities on evacuation by lifts
}

\author{
Martin Szénay, Martin Lopušniak \\ Institute of Architectural Engineering, Faculty of Civil Engineering, Technical University of Kosice \\ Vysokoskolska 4, 042 00, Kosice, Slovak Republic \\ matrin.szenay@tuke.sk; martin.lopusniak@tuke.sk
}

\begin{abstract}
In 2010 it was defined five challenges for the solution of evacuation of persons in buildings to 2020 . One of the challenges is to implement helpfull technologies during evacuations from buildings - lifts. Needed steps for fulfilling this challenge are also quantification of missing data which are dealing with evacuation of persons with disabilities. From 2002 all public buildings in Slovak Republic have to be also accessible to persons with disabilities, but it is also a global problem. In present exists just small number of informations of movement parameters of persons with disabilities during evacuation by lift. There for, this work was focused on collecting these informations. The data collection was realized by using an in-situ experiment. The aim of the work was to quantify the phase stages of evacuation by elevators for persons with disabilities (speed, time, movement and capacity parameters). Person's movements were monitored during the measurements, arrival to lift, cabin entry and exit from the cabin, including leaving the bounded area. Arrival to lift included movement in the bounded area in front of the lift, until the moment of pushing the button was pressed to call the lift. The time of cabin entering includes the time from the beginning of opening the lift doors to the beginning of closing of the lift doors. The exit from the cabin includes the time from opening the lift doors, passing through the lift doors to leaving the bounded area. In total, ten participating persons in the experiments imitated wheelchair movement and movement with leg fracture. Measurements were made on two lifts, where person evacuating himself or with the help of another person. Everyone performed each measurement three times. A total of 720 measurements were performed in the work. According to the results of the experiment it can be stated that cabin entry is longer for a person on the wheelchair than for a person with a leg fracture, but the difference is even bigger during exit from the cabin, including leaving the bounded area. During the experiment, various movement techniques have been observed that may affect their overall the time of cabin entry and exit from the cabin. Obtained results can extend existing evacuation model to the possibility of using the lift. The obtained results quantify the individual phase stages of entering to the lift and exiting of the lift for persons with limited movement.
\end{abstract}

Keywords: Lift evacuation, Experiment, Movement parameters, Persons with disabilities, Evacuation time

\section{Introduction}

Passenger lifts are not used to their full potential [1]. Passenger lifts are allowed for evacuation except in exceptional cases and under specific conditions. In most cases related to buildings, people are forced to use staircases for evacuation. In this way buildings represent a series of challenges for safe evacuation, mainly based on 2 reasons - limitations of movement from the point of view of persons mobility impairments [2][3], or fatigue during movement downstairs [4]. According to the Slovak standard, three groups of people movement properties are taken into account. The first group includes persons able to move alone. The "persons of limited mobility" belong to the second group. Persons, whose evacuation is more demanding than in the case of other persons. Old people, children, disabled persons of limited mobility are an example of this group. The third group includes "immobile persons". Persons, whose evacuation is possible only with help of other persons. For example, mentally affected persons, in-patients at clinics with serious health states, persons temporarily unable to move, infants, 
toddlers and the like belong to this group. According to the Statistical Office [5], almost $20 \%$ of inhabitants are persons in the old pension age (62 years and more), and $12 \%$ of inhabitants are persons of the school age (4 to 15 years) in Slovakia in 2017. Altogether at least one third of inhabitants of the Slovak Republic can be considered persons of limited mobitlity in the case of the proposal of escape routes. Evacuation using stairs is difficult and practically impossible without assistance of other person for the persons of limited mobility, for example on wheelchair. Lifts are inevitable for evacuation of persons of limited mobility. This leads to shortening of the overall evacuation time.

In 2010, Averil [6] defined several necessary steps to cope with large challenges presented by the solution of evacuation in buildings. The quantification of missing data dealing with evacuation of persons using lifts is one of these steps. Up to the present day, several papers and studies on evacuation of persons using lifts were carried out based on simulated calculations or in-situ experiments. In their paper, Ding N. et al [1] established objectives to ascertain how evacuated persons behave and factors affecting their behaviour during fire and evacuation. They decided to carry out a real experiment using simulated conditions of fire, where the lift should be used by persons for evacuation. In this way this study was able to obtain data about time of get in and get out of the lift, time of opening and closing the lift door and behaviour of persons during the formation of a queue. According to results of the study, time of getting into the lift was shorter than time of opening and closing the door. They have also ascertained that the number of evacuated persons affects their behaviour, but presence of smoke not. The shape of queue of persons has influence on time of passage of persons through the lift door - the shape of a curve is quicker than the shape of a line. Study by Ding Y. et al [7] can served as another example in this field, where simulation software was used to ascertain, beside others, which ratio of persons using the lift and staircase has the most favourable effect on the course of evacuation. Therefore they modelled in their work 28 -storey building with the staircase and 2 lifts. Their work also included different age groups of people. They said that the simulation results show that the optimal percentages of the occupants evacuated by the lifts, when achieving the shortest evacuation time, is almost not related to the number of evacuated persons and floors. Further, when focusing on age groups, it was ascertained that if older persons used the lift, the staircase will not be significantly overloaded. At the same time, if the lift is used by children, the rate of its use will be improved. Therefore the selection of portion of persons by age categories, who should be evacuated by the lift can reduce congestions on staircase, and effectively speed up the evacuation process. Papers by Heyes [8], Kinsey et al. [9] and Jönsson et all [10] paid attention to waiting problems and they have demonstrated that people prefer the use of lifts during evacuation instead of staircases, but they are not willing to wait for the lift too long. It is anticipated that 90 to $97 \%$ of people will not wait longer than 5 minutes. The choice to wait is increased with the increasing height of the building - people are willing to wait for a longer period of time on higher floors than on lower ones. For example in the next study using the simulation tool, Andrée et al [11] focused on the high-rise building, selection of exits and waiting time for evacuation lifts. Their objective was to examine, inter alia, effect of the lighting system on the selection of exits and to quantify waiting time for lifts. The study resulted into the fact that the well and simply designed system of marking escape routes will affect the selection of an exit. This system can also be used for increasing the portion of people, who will decide for the evacuation lift as the first choice of escape. Further, their results have demonstrated that people were willing to wait for the lift up to 5 minutes, but if they decided to wait, their waiting is usually extended to 20 minutes and more. When evacuating by lift it's needed to focus on people for whom the lift is a necessary device person with limited mobility . Galea et al. [12] and Hedman [13] dealt with the details of the persons movement with limited mobility to stairs and floors. The evacuation movement of under six years children was studied by Larusdottir a Dederichs [14]. These studies have shown that the movement speed of persons with limitied mobility is different from that of healthy persons.

In general, the evacuation process using lifts consists of phases. For example time of getting in or getting out can considerably differ during evacuation from normal conditions. In this way, during the existence of danger, the entire process of evacuation can be decelerated, for example evacuated persons do not want to leave the lift cabin, when overload signal is indicated [7]. Results of previous examinations have demonstrated potential of lifts for evacuation of persons. However, in all aforementioned papers 
they call attention to the need of quantification of other movement parameters and description of the entire process using a suitable algorithm that could be used for simple, but also complex calculation models.

As it was stated above, approximately $30 \%$ of inhabitants in the Slovak Republic are person of limited mobility. According to laws, they should have available accessible evacuation routes that do not prevent their movement. Therefore lifts are inevitable for the solution of evacuation. But no relevant information on movement parameters of persons of limited mobility exists for assessment of calculations. This is why our work was focused on collection of this information, particularly on the quantification of selected phases of evacuation using lifts - time of movement for persons of limited mobility. The in-situ experimental method was used for collection of data, where movements of persons were monitored - time of arrival to the lift, time of getting into the cabin and time of getting out of the cabin including leaving the defined area.

\section{The method used}

The lift evacuation process consists of phase stages. The total evaciutaion time consists of walking and moving movements that are directly related to the lift. Lift-related movement involves both walking and moving the lift cabin. The movement of lifts mechanisms cannot be affected by persons. Conversely, the behavior of persons may affect the time of entry or exit from lift.

\subsection{Description of experiment and scenarios}

Ten persons participated in experiment ( 7 men and 3 women) and imitated the movement of people with limited mobility - the movement in a wheelchair and the movement of an injured person (broken leg). None of the participants involved in the experiment had experienced using a wheelchair prior to the experiment. In contrast, three participants confirmed that they had to use a crutch or a support stick at least once in their lives. We examined two different alternatives of evacuation. In the first alternative, the person with limited mobility moved alone, without any assistance from another person. The second alternative included an accompanying person assisting the person with limited mobility. In this case, the accompanying person had no mobility limitation. The task of this person is to push the person on wheelchair and to support the person with broken leg. In all measurements, persons moved like during dangers - evacuation behaviour. During experiment, two passenger lifts were selected in the university building - identified as L1 and L2, respectively. Dimensions of the lift cabin L1 are $1.00 \times 1.26 \mathrm{~m}$ and the clear width of the door is $0.78 \mathrm{~m}$ (Fig. 1). The prescribed maximum capacity of this lift is 6 persons. Dimensions of the lift cabin L2 are $1.10 \times 1.40 \mathrm{~m}$ and the clear width of the door is $0.78 \mathrm{~m}$ (Fig. 1). The prescribed maximum capacity of this lift is 8 persons. A measurable area was marked in front of both lifts representing the nearest surrounding of the lift, where change of movement nature occurs (slowing down, change of direction and the like). Dimensions for the L1 lift were selected as $2.35 \times 3 \mathrm{~m}$ and for the L2 lift $3 \times 3$ m (Fig. 2).
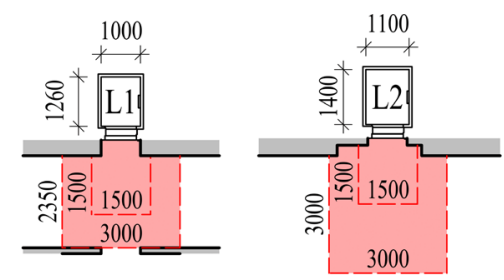

Fig. 1: Scheme of measurable areas and dimensions of lifts L1 and L2

The entire experiment included 8 scenarios. All persons carried out each measurement 3 times. In total, 720 measurements were carried out for 8 scenarios and three monitored phases. Normal mechanical wheel chair was used for the imitation of movement of the person on the wheel chair. This wheel chair belongs to the category of standard wheel chairs with folding frame and seat width of $0.4 \mathrm{~m}$. Crutches of two different sizes and ortheses were used for imitation of movement of the injured person. These means 
should ensure that the person's leg was fixed against movement, and could not be bent in the elbow. This fixation of the leg can represent for example the broken leg in plaster.

\subsection{Description of experiment}

The objective of measurement was to quantify time values of selected phases:

- Arrival to the lift

- Getting into the lift cabin

- Getting out of the lift cabin and leaving the area

The work was focused only on the determination of values of movement time under standard conditions. Areas were sufficiently lighted by day and artificial lighting. Times of travelling in the lift from one floor to another one were also not monitored. This is why the experiment was carried out only on one floor of the building, where movements were monitored during phases.

Arrival to the lift - time No. 1 "D1" (Fig. 2): This time included motion in the measured area. The procedure was as follows: The person with disabilities stood outside the measured area, where he/she started his/her movement towards the lift. Subsequently, this person crossed the boundary of the area, which represents the beginning of measured time D1. In this way, the person could autonomously move in this area in order he/she could get as soon ans possible to the lift door with the panel intended for opening the door. The person standing in front of the door had to slow down his/her movement, and subsequently to stop. As the last, he/she had to press the button on the lift panel to call the lift or to open the lift door. The moment of pressing the button means the end of measured time D1.

Getting into the lift cabin - time No. 3 "D3" (Fig. 2): This period included time of door opening and time of movement of the person to inside of the lift cabin. The procedure was as follows: The person with disabilities stood in the measured area in front of the closed lift door prepared for opening the door. Subsequently, this person opened the lift door by pressing the button on the lift panel, which represents the beginning of measured time D3. This person had to wait until the door is fully opened, and he/she could start his/her movement towards inside of the cabin. When this person passed through the door, and was present in the cabin, he/she had to stop his/her movement before the cabin panel. This person, as the last one, had to press buttons located on the cabin panel, by which he/she selected the exit station, and closed the lift door. The moment of pressing the button intended for closing the door represents the end of measured time D3.

Getting out of the lift cabin - time No. 5 "D5" (Fig. 2): This period included time of door opening and time of movement of the person from the lift cabin up to outside the measured area. The person with disabilities stood in the lift cabin with the closed door prepared for opening the door. Subsequently, this person opened the lift door by pressing the button on the cabin panel, which represents the beginning of measured time D5. This person had to wait until the door is fully opened, and he/she could start his/her movement out of the cabin. The person on wheel chair had to reverse, because the cabin space does not allow any turn on the wheel chair. When this person got out of the cabin, he/she had to stop his/her movement, and had to turn by approx. $90^{\circ}$ in the direction, in which he/she wanted to leave the measured area. Subsequently, the person started his/her movement, and passed through the area boundary. On the contrary, the person with injured leg can stand face the door, because dimensions of the cabin allow turning of this person. Subsequently, the person started his/her movement in the cabin and passed through the area boundary without necessary stop and turning. The moment of passing the area boundary represents the end of measured time D5.

If the person on wheel chair is accompanied by another person, movement was provided just by this accompanying person. In the case of the person with injured leg, the accompanying person served as a support during movement. In this way the pressing of button was based on free will of participants. 


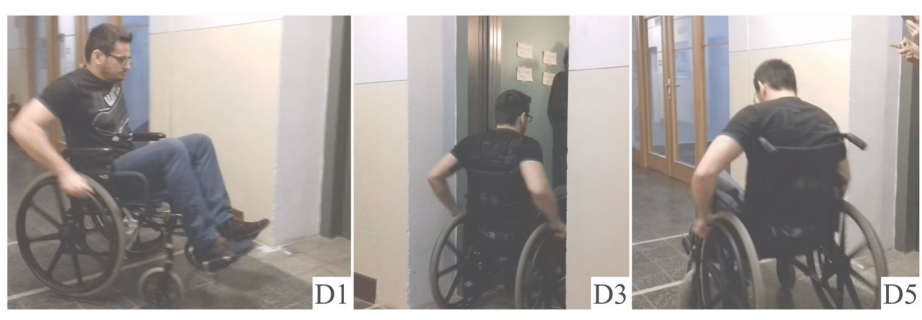

Fig. 2: A specimen of measurements of selected phases

\section{Results and discussion}

During measurements, the following values of time of phases were obtained for the person on wheel chair without accompanying person and with accompanying person, for the injured person without accompanying person and with accompanying person. In addition to the above, average, maximum and minimum measured time values of phases are depicted for the person on wheelchair and the injured person (Tab. 1).

Tab. 1: Average, maximum and minimum measured times for person on wheelchair and injured person; (1ppersons without the accompanying person; $2 p-$ with the accompanying person)

\begin{tabular}{lllllll}
\hline Persons on the wheelchair & $\mathbf{D 1 - 1 p}$ & $\mathbf{D 3 - 1 p}$ & $\mathbf{D 5 - 1 p}$ & $\mathbf{D 1 - 2 p}$ & $\mathbf{D 3 - 2 p}$ & $\mathbf{D 5 - 2 p}$ \\
Average time & $3.84 \mathrm{~s}$ & $7.00 \mathrm{~s}$ & $10.00 \mathrm{~s}$ & $2.44 \mathrm{~s}$ & $5.57 \mathrm{~s}$ & $6.78 \mathrm{~s}$ \\
Maximum time & $7.80 \mathrm{~s}$ & $11.55 \mathrm{~s}$ & $15.25 \mathrm{~s}$ & $3.29 \mathrm{~s}$ & $7.44 \mathrm{~s}$ & $8.18 \mathrm{~s}$ \\
Minimum time & $1.98 \mathrm{~s}$ & $4.95 \mathrm{~s}$ & $6.80 \mathrm{~s}$ & $1.38 \mathrm{~s}$ & $4.35 \mathrm{~s}$ & $2.28 \mathrm{~s}$ \\
Max. and min. difference & $5.82 \mathrm{~s}$ & $6.60 \mathrm{~s}$ & $8.45 \mathrm{~s}$ & $1.91 \mathrm{~s}$ & $3.09 \mathrm{~s}$ & $5.90 \mathrm{~s}$ \\
Injured persons & $\mathbf{D 1 - 1 p}$ & $\mathbf{D 3 - 1 p}$ & $\mathbf{D 5 - 1 p}$ & $\mathbf{D 1 - 2 p}$ & $\mathbf{D 3 - 2 p}$ & $\mathbf{D 5 - 2 p}$ \\
Average time & $3.40 \mathrm{~s}$ & $5.51 \mathrm{~s}$ & $5.89 \mathrm{~s}$ & $3.16 \mathrm{~s}$ & $5.98 \mathrm{~s}$ & $6.72 \mathrm{~s}$ \\
Maximum time & $5.53 \mathrm{~s}$ & $7.13 \mathrm{~s}$ & $8.70 \mathrm{~s}$ & $4.36 \mathrm{~s}$ & $8.18 \mathrm{~s}$ & $8.49 \mathrm{~s}$ \\
Minimum time & $2.30 \mathrm{~s}$ & $3.06 \mathrm{~s}$ & $4.14 \mathrm{~s}$ & $2.16 \mathrm{~s}$ & $4.73 \mathrm{~s}$ & $4.63 \mathrm{~s}$ \\
Max. and min. difference & $3.23 \mathrm{~s}$ & $4.07 \mathrm{~s}$ & $4.56 \mathrm{~s}$ & $2.20 \mathrm{~s}$ & $3.45 \mathrm{~s}$ & $3.86 \mathrm{~s}$ \\
\hline
\end{tabular}

When measuring arrival to the lift, time of movement for the person on wheelchair was longer than for the injured person. This can be caused by the fact that the person must manoeuvre with the wheelchair during movement. For example, closely in front of the lift door, it was necessary slightly slew the wheelchair in order the person would face the lift. This results in slowing down during movement. On the contrary, the injured person moved straightly to the lift practically without noticed interruption. This person slowed down only in front of the lift door. In the case of the person on wheelchair, average time of getting into the lift cabin was longer than for the person with leg injury (Fig. 6a; difference was $1.5 \mathrm{~s}-$ $21 \%$ ). This was caused by the fact that the person on wheel chair had tight conditions for passage through the lift door against the injured person. During manoeuvring, some persons on wheelchair bumped into the frame and lift door, by which they slowed down their movement, and sometimes they even had stopped. Maximum time of $11.55 \mathrm{~s}$ for getting in was recorded, when the person stood in the door for almost $4 \mathrm{~s}$, and could not move. In the contrary, the injured person could adapt his/her width during passage through the door facilitating the getting in process - the maximum measured time value was 7.13 s. In the case of getting out of the cabin, the difference against the getting in was twofold (Fig. 6a; $4.11 \mathrm{~s}$ $-41 \%)$. The reason was based on the fact that the person had to reverse out of the cabin, stop in the measured area, turn, and only then he/she could to continue in movement to the area boundary. Problems with bumping the frame and door of the lift occurred like in the case of getting into and and getting out of the cabin. This is why the maximum time achieved the value of $15.25 \mathrm{~s}$, when the person was nipped by the lift door during his/her passage trough the door. On the contrary, the injured person could move practically without any interruption of movement directly to the area boundary - maximum measured time value of movement was $8.70 \mathrm{~s}$. In the case of immobile person with accompanying person (Fig 6a), 
time differences in the nature of limitation were smaller than in previous cases. Differences were as follows: In the case of arrival to the lift this was $0.71 \mathrm{~s}(23 \%)$. In the case of getting into the lift this was $0.41 \mathrm{~s}(7 \%)$. In the case of getting out of the lift this was $0.05 \mathrm{~s}(1 \%)$. It is possible to conclude that time values for getting in and getting out with the accompanying person are almost the same both for the person on wheelchair and the injured person.

In the case of arrival to the lift, it is possible to speak about negligible influence of the accompanying person on time of movement of the injured person, because the difference is only $0.25 \mathrm{~s}(7 \%)$ in favour of the case with the accompanying person (Fig. 6b). The presence of the accompanying person had influence on shortening the time of movement for the person on wheelchair (Fig. 6b). Difference was $1.40 \mathrm{~s}(36 \%)$ for arrival to the lift, $1.43 \mathrm{~s}(20 \%)$ for getting into the lift and $3.22 \mathrm{~s}(32 \%)$ for getting out of the cabin. It was caused by the fact that the person on wheelchair without accompanying person moves slower. But the accompanying person can push the person on wheelchair without any apparent movement problems higher acceleration, higher speed, higher slow down. When getting into the lift cabin, the accompanying person almost always manoeuvred with wheelchair without bumping the frame of lift door. When getting out of the lift cabin, the accompanying person could reverse more quickly, turn and start up with the wheelchair. However, the presence of the accompanying person influences time of getting in and out for the injured person. Difference was $0.48 \mathrm{~s}(8 \%)$ for getting into the lift, $0.83 \mathrm{~s}(12 \%)$ for getting out of the lift. The main reason is based on the fact that two persons must pass through the lift door with the width of $0.78 \mathrm{~m}$. During normal movement, the injured person and accompanying person stood next to each other, and walked ahead. During passage through the lift door, both persons had to slew in order they could get into the lift door. The crutch hampered movement, for example it was caught by the door near the floor, and the person had to manoeuvre more with it. Both facts resulted in slowing down the movement. The single person passed almost always without slowing down, because width of the door is sufficient for his/her.

a)

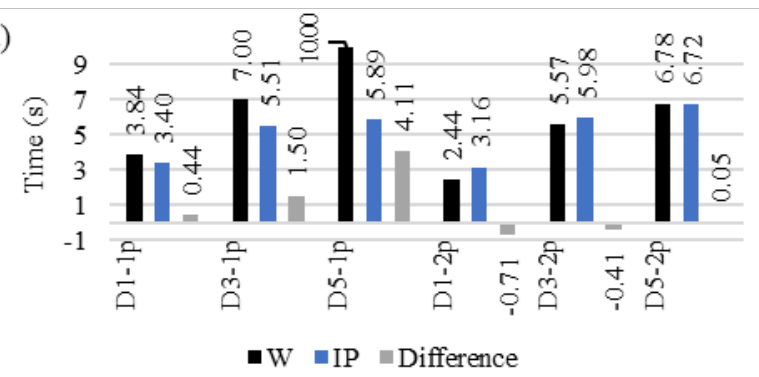

b)

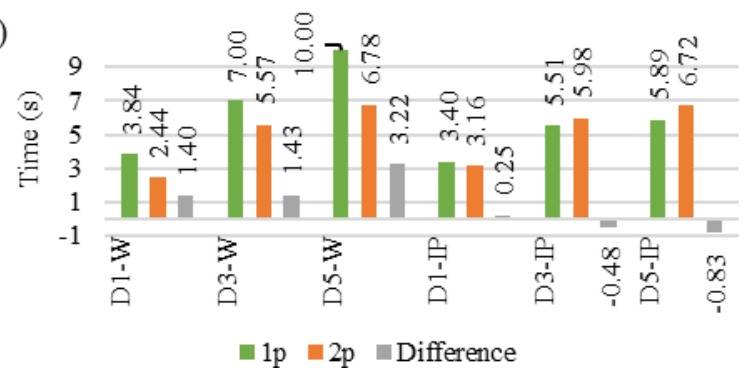

Fig. 6: Comparison of average times - a) persons on wheel chair (W) and injured persons (IP); b) persons without the accompanying (1p) person and with the accompanying person ( $2 \mathrm{p})$

When comparing gender of persons with disabilities, it was ascertained that time of movement of women was longer than time of movement of men, if persons with disabilities had not any accompanying persons (Fig. 7). Maximum difference was $1.43 \mathrm{~s}$ (29\%) and minimum difference was $0.24 \mathrm{~s}(4 \%)$. On the other hand, time of movement of women was shorter than time of movement of men, if the persons with disabilities had accompanying person (Fig. 7). Maximum difference was $0.44 \mathrm{~s} \mathrm{(8 \% )} \mathrm{and} \mathrm{minimum}$ difference was $0 \mathrm{~s}(0 \%)$. The accompanying person declared that pushing and braking the wheel chair with sitting woman was easier than with sitting man. This was valid even in the case of transfer of weight from the injured person to the accompanying person. The accompanying person declared that it was physically more demanding to support a man weighing from 70 to $90 \mathrm{~kg}$ than a women weighing from 50 to $70 \mathrm{~kg}$. 
a)

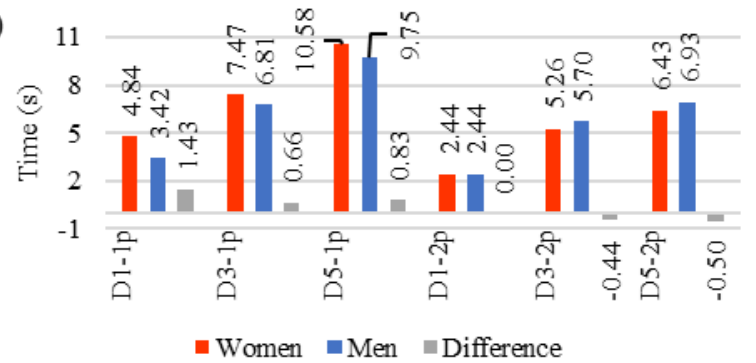

b)

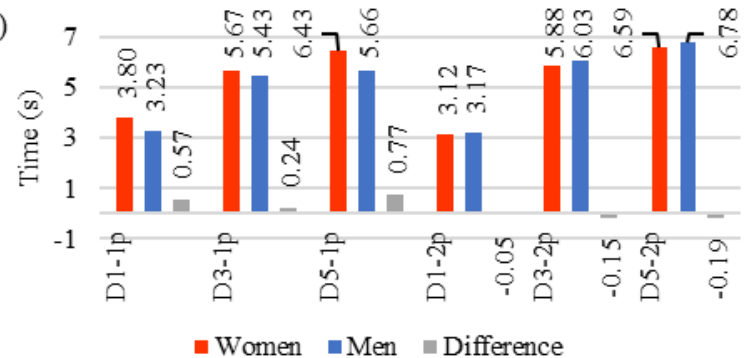

Fig. 7: Average times for $-a)$ person on wheel chair; $b)$ injured person; $(1 \mathrm{p}-$ persons without the accompanying person; $2 \mathrm{p}-$ with the accompanying person)

Different techniques of movement of persons on wheelchair were observed during measurements. Some persons had problem with movement during passage through the door. Therefore they decided, in other trials, to grasp the lift door with hands, and to draw subsequently into the cabin (Fig. 8a). In this way the person could avoid bumping by the wheel chair to the lift door. The situation related to the accompanying of the person on wheelchair during arrival to the lift was another interesting thing. This interesting thing is based on the fact, which person would press the button on the lift panel. If the button was pressed by the person with disabilities, no delay of movement occurred (Fig. 8b). On the contrary, when the button was pressed by the accompanying person, slowing down by approx. 0.5 to $1 \mathrm{~s}$ was observed. This happened because the accompanying person had to stop the wheel chair, to bypass it or to lean. Even then the accompanying person could press the button on the lift panel (Fig. 8c).

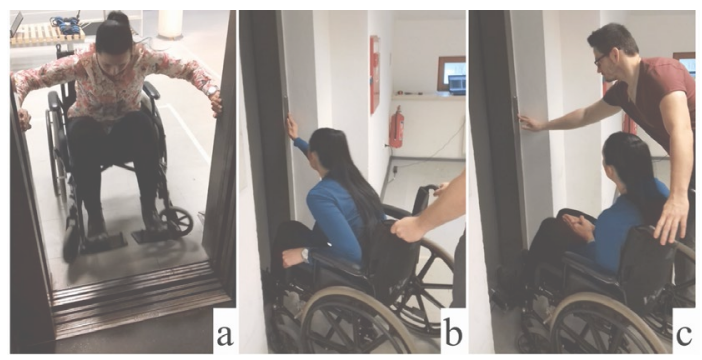

Fig. 8: a) - Getting into the cabin using hands, b) - the person with disabilities is pressing the button, c) - the accompanying person is pressing the the button.

\section{Conclusion}

The work is focused on obtaining time value of phases of movement for persons with disabilities. Phases were analysed, particularly arrival to the lift, getting into the lift cabin and getting out of the lift cabin. Phase stage of getting into the lift and getting out of the lift also include time of opening the door. Average time of getting into the lift was for the person on wheel chair longer by $21 \%$ than for the injured person. In the case of getting out of the cabin, this difference was up to $41 \%$. If any hesitations occurred during passage through the door, resulting time was longer against average time by $65 \%$ for the person on wheel chair and by $48 \%$ for the injured person. It has also been ascertained that the presence of the accompanying person had effect on shortening the time of movement for the person on wheel chair by $36 \%$. However, in the case of injured person, time was expanded by $12 \%$. Different methods of movement of women and men were observed during the measurements. This was reflected in the mean movement time, which was $30 \%$ longer for women than for men.

Measured data apply to persons who may suddenly lose the ability to move without restriction. The sample of persons examined was from 26 to 40 years old and at the same time, they were physically healthy without movement limitation. These persons have never had a experience to movement on wheelchair. Selected lifts did not allow the turning of persons on wheelchair. In the future, it will be 
necessary to expand results by the use of larger lifts (for example for two persons with disabilities). It is also necessary to focus on the other types of movement limitation.

\section{Acknowledgements}

This work was supported by grant project 2/0042/17 "Solar energy influences and integrated envelopes on the quality of the environment in buildings and cities."

This paper was created thanks to the financial support from the EU Structural Funds, through the R\&D Operational Program and project OPVaV-2008/2.2/01-SORO "Architectural, engineering, technological and economic aspects of the design of energy efficient buildings", codenamed ITMS: 26220220050; which is financed by EC funds.

\section{References}

[1] N. Ding, T. Chen, H. Zhang. "Experimental Study of Elevator Loading and Unloading Time During Evacuation in High-Rise Buildings" Fire technology, vol. 53, is. 1, pp. 29-42, May 2016.

[2] K.E. Dunlop, T.J. Shields. "Real fire emergency evacuation of disabled people" in Proceedings of CIB W14 International Symposium and Workshops on Engineering Fire Safety in the Process of Design Equivalency, 1993, pp. 157-164.

[3] T.J. Shields, K.E. Boyce, N. McConnell. "The behaviour and evacuation experience of WTC 9/11 evacuees with self-designated mobility impairments" Fire Safety Journal, vol. 44, is. 9, pp. 881-893, May 2009.

[4] J. Averill, D. Mileti, R. Peacock. "Federal Building and Fire Safety Investigation of the World Trade Center Disaster: Occupant Behaviour, Egress, and Emergency Communication” Internet: https://ws680.nist.gov/publication/get pdf.cfm?pub id=101046, December 01, 2005 [May 17, 2018].

[5] "Statistical Office of the Slovak Republic" Internet: https://slovak.statistics.sk, [May 17, 2018]

[6] J.D. Averill. "Five Grand Challenges in Pedestrian and Evacuation Dynamics" in Pedestrian and Evacuation Dynamics, 2011, pp. 1-11.

[7] Y. Ding, L. Yang, F. Weng, Z. Fu, P. Rao. "Investigation of combined stairs elevators evacuation strategies for high rise buildings based on simulation" Simulation Modelling Practice and Theory, vol. 53, pp. 60-73, February 2015.

[8] E. Heyes. "Human Behaviour Considerations in the Use of Lifts for Evacuation from High Rise Commercial Buildings" PhD. thesis, University of Canterbury, Christchurch, New Zealand, 2009.

[9] M.J. Kinsey, E.R. Galea, P.J. Lawrence. "Stairs or lifts? A study of human factors associated with lift/elevator usage during evacuations using an online survey" Internet:

http://www.fseg.gre.ac.uk/fire/fseg ped2010 liftstairchoice paper distrib final final.pdf, [May 17, 2018]

[10] A. Jönsson, J. Andersson, D. Nilsson. "A risk perception analysis of elevator evacuation in high-rise buildings" In Proceedings of the 5th International Symposium on Human Behaviour in Fire, 2012, pp. 398-409.

[11] K. Andrée, D. Nilsson, J. Eriksson. "Evacuation experiments in a virtual reality high-rise building: Exit choice and waiting time for evacuation elevators" Fire and Materials, vol. 40, is. 4, pp. 554-567, May 2015.

[12] E.R. Galea, A.P.M. Adams: "An Experimental Evaluation of Movement Devices used to assist People with Reduced Mobility in High-Rise Building Evacuations" In Pedestrian and Evacuation Dynamics, 2011, pp. 129-138.

[13] G.E. Hedman: "Travel Along Stairs by Individuals with Disabilities: A Summary of Devices Used During Routine Travel and Travel During Emergencies" In Pedestrian and Evacuation Dynamics, 2011, pp. 109-119.

[14] A.R. Larusdottir, A.S. Dederichs: "Evacuation Dynamics of Children - Walking Speeds, Flows Through Doors in Daycare Centers" In Pedestrian and Evacuation Dynamics, 2011, pp. 139-147. 